\title{
Alternating Combination Chemotherapy and Radiotherapy in Locoregionally Advanced Head and Neck Cancer
}

\author{
Hanan Gamal-Eldin Mostafa, Mohamed Abdel Hakeem Mekkawy, Samir Shehata M. Eid, \\ Hussein El-Weshahy and Ola Nabeeh Abdel-Fatah
}

\author{
Department of Clinical Oncology and Nuclear Medicine, Department of ENT Surgery, Faculty of \\ Medicine, Assiut University
}

Background: Alternating chemotherapy and radiotherapy is a minor variation of concurrent chemoradiation. This schedule has been tested in advanced head and neck cancer and has shown superiority over standard radiation in some randomized trials with only marginaly greater toxicity. In this study the efficacy and toxicity of alternating chemotherapy and radiotherapy in advanced head and neck cancer was evaluated.

Patients and methods: The study was conducted between 2002 and 2005 at the Clinical Oncology Department of Assiut University Hospital, to explore the activity of the schedule of alternating chemotherapy and radiotherapy. Radiotherapy consisted of $60 \mathrm{~Gy}, 2 \mathrm{~Gy} /$ fraction, 5 fractions/week (weeks 2-3, 5-6, 8-9) alternated with four courses of chemotherapy consisted of IV vinblastine $6 \mathrm{mg} / \mathrm{m}^{2}$. followed 6 hours later by IM bleomycin 30IU, day1, IV methotrexate 200mg day2, IV leucovorin rescue, day 3 (weeks 1, 4, 7, 10).

Results: Fifty patients with stage III \& stage IVA unresectable head and neck cancer were included. Complete response was $72 \%$, partial response $18 \%$, stable disease $1 \%$ and progressive disease $8 \%$. Main grade 3-4 toxicities were: stomatitis $32 \%$, dysphagia $28 \%$, xerostomia $6 \%$ and anemia $14 \%$. At a median follow-up of 38 months, 3-year overall survival and disease free survival were $32 \%$ and $30 \%$, respectively. Prognostic factors significant for response and survival were ECOG performance status, pathological grade, anatomical site, node stage and disease stage.

Conclusion: Alernating chemotheraby and radiotherapy with vinblastine, methotrexate and bleomycin shows very promising activity and low toxicity in locally advanced head and neck cancer treatment.

Key words: alternating chemoradiotherapy, head and neck, squamous cell carcinoma, locally advanced Corresponding Author: Hanan Gamal E-mail: mostafahanan36@yahoo.com

\section{INTRODUCTION}

Head and neck cancer (HNC) is the sixth most common cancer worldwide. Head and neck cancer can originate in the skin or soft tissue, in the upper aerodigestive tracts (oral cavity, oropharynx, hypopharynx, larynx, nasopharynx paranasal sinuses, salivary glands), or in the thyroid ${ }^{1}$. Demographic and geographic factors as well as exposure to different carcinogens (e.g. nicotine, alcohol, viruses) contribute to the differential incidence of these tumors ${ }^{2}$.

As a rule, early-stage (stage I and II) HNC should be managed with a single modality, while advanced tumors are managed with multimodality therapy. Advanced hypopharyngeal or laryngeal squamous cell carcinomas are preferentially managed by surgery followed by radiotherapy or concurrent chemoradiation as organ preservation $^{3}$.

Rapidly alternating chemotherapy and radiotherapy (ACR) is a minor variation of concurrent
chemoradiation(CCR) aimed at minimizing toxicity. This scheduling allows uninterrupted treatment of the tumor, with radiotherapy administered during the pauses between cycles of chemotherapy ${ }^{4}$. One of the first randomized trials showing a significant survival advantage induced by chemoradiation in advanced (HNC) was one of rapidly alternating chemotherapy and radiotherapy ${ }^{5}$.

Decreasing chemoradiation induced toxicity is a major objective in (HNC). Chemoradiation has proven to be superior to radiotherapy alone, but treatment-related toxicities are higher, and an expert staff is required to deliver this complex treatment modality ${ }^{6,7}$.

The objective of the present study was to assess the efficacy of alternating chemoradiotherapy, treatment toxicity, survival and prognostic factors of patients with locally advanced head and neck cancer. 


\section{Vol. 8| No. 1-2 2012}

\section{PATIENS AND METHODS}

\section{Selection of patients:}

Patients were selected if they met the following criteria: histopathologically-proven squamous-cell carcinoma of the larynx or hypopharynx; stage III and IVA according to the American Joint Committe (AJCC) 2002 staging system, age $<70$, Eastern Cooperative Oncology Group (ECOG) performance status 0 or 1 , no previous surgery, radiotherapy and/or chemotherapy, and written informed consent. All eligible patients were included in the study.

Pretreatment evaluation included complete history, physical and ENT examination, complete blood count, liver and kidney function tests, chest X-ray. Computerized tomography and/or sonogram were performed when indicated.

\section{Treatment:}

Radiotherapy consisted of 60 Gy (two-dimensional treatment) delivered as a daily single dose of 2 Gy, five times a week (acceptable dose with ACR), during weeks 2-3, 5-6, and 8-9(two-dimensions). Patients were treated with $6 \mathrm{MV}$ photons. The primary site and upper-midneck nodes were treated with shrinking field technique with lateral parallel opposed photon fields (50Gy). The lower neck-supraclavicular regions were treated with an oppositional antero-posterior field (50 Gy). Areas of macroscopic disease were boosted for an additional 10 Gy at 2 Gy per fraction. The dose to the spinal cord was to be limited to $40 \mathrm{~Gy}$.

Chemotherapy regimen consisted of vinblastine $6 \mathrm{mg} / \mathrm{m}^{2}$ IV followed 6 hours later by bleomycin $30 \mathrm{IU}$ IM day 1 , methorexate $200 \mathrm{mg}$ IV day 2 , leucovorin rescue $5 \mathrm{mg} / \mathrm{m}^{2} \mathrm{IM}$ every 6 hours day 3 . Chemotherapy was given during weeks $1,4,7,10$.

\section{Evaluation of response and toxicity:}

Response was assessed 6 weeks after the end of treatment by repeating the method for staging according to World Health Organization criteria. Toxicities were evaluated according to EORTC/RTOG toxicity criteria 1995 and National Cancer Institute (NCI) common toxicity criteria version 2.0, 1998.

\section{Statistical methods:}

The primary end point of this study was complete response rate assessment. Response was assessed according to World Health Organization (WHO) criteria ${ }^{8}$. Secondary end points were overall survival and disease-free survival. Chi-square test was used to compare differences in distribution of frequencies among various groups of response. $P$-value 0.05 was considered significant. Overall survival and disease-free survival were calculated using Kaplan-Meier method'.
Hanan Gamal-Eldin et al.

Disease-free survival was calculated from the time of treatment beginning until the time of disease progression at any site including the occurrence of metastases.

Overall survival was calculated from the time of treatment beginning until time of death or last follow-up.

\section{RESULTS}

From December 2002 to July 2005 at Oncology Department in Assiut University Hospital, 50 patients with locoregionally advanced laryngeal and hypopharyngeal cancer entered the study. Sample size was estimated based on the prevelance of squamous cell carcinoma cases who attended the hospital. All patients were examined to sort out the eligible cases. All eligible cases were included in the study.

Table (1) shows the main patients characteristics.

Tumor and nodal staging is presented in Table (2).

Anatomical site and pathological tumor grading are presented in Table (3).

As regard response rate to treatment, thirty-six patients had a complete response $(72 \%)$, nine patients had partial response $(18 \%)$, one patient had stable disease $(2 \%)$ and 4 patients had progressive disease $(8 \%)$.

Table (4) shows the significant prognostic factors for response. The stage of the disease, nodal status and anatomical site were significant prognostic factors for response.

Table (5) shows the toxicity of radiotherapy and its frequency according to RTOG/EROTC toxicity criteria 1995.

Table (6) shows the grades of toxicity of chemotherapy and their frequency according to (NCI) grading of toxicity 1998.

At a median follow-up of 38 months, nine patients (18\%) had progression at the tumor site and in four of these patients a recurrence in the lymph nodes of the neck was also observed. Metastases were detected in seven patients $(14 \%)$, three patients had metastasis in the lung and four in the bone. They were treated by systemic chemotherapy. Three-years overall survival (OS) and disease-free survival (DFS) were 32\% and $30 \%$, respectively figure $(1,2)$.

Prognostic factors for survival were performance status, anatomical site, nodal status, pathological grade and stage of the disease (Figures 3-7). 


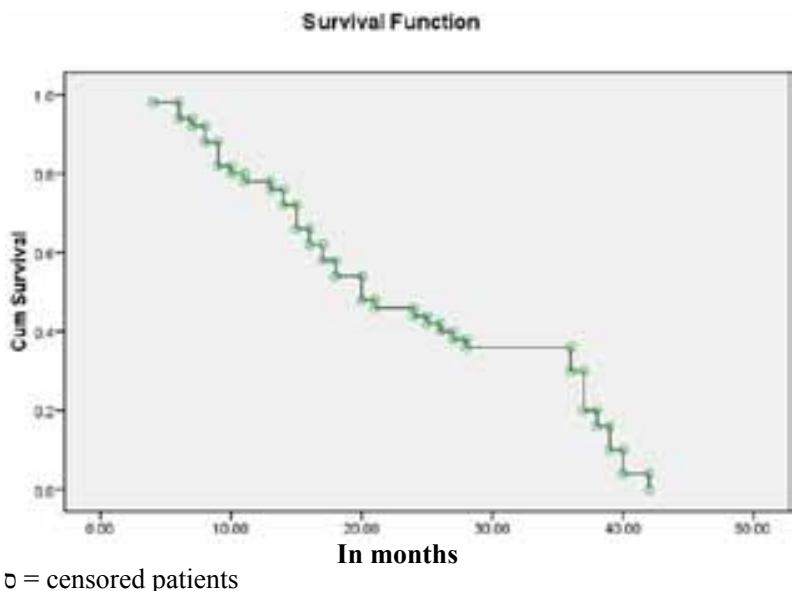

Figure 1: Overall survival (OS) of 50 patients with locally advanced head and neck cancer treated by alternating chemoradiotherapy.

$-95 \%$ confidence interval 13.076-26.924.

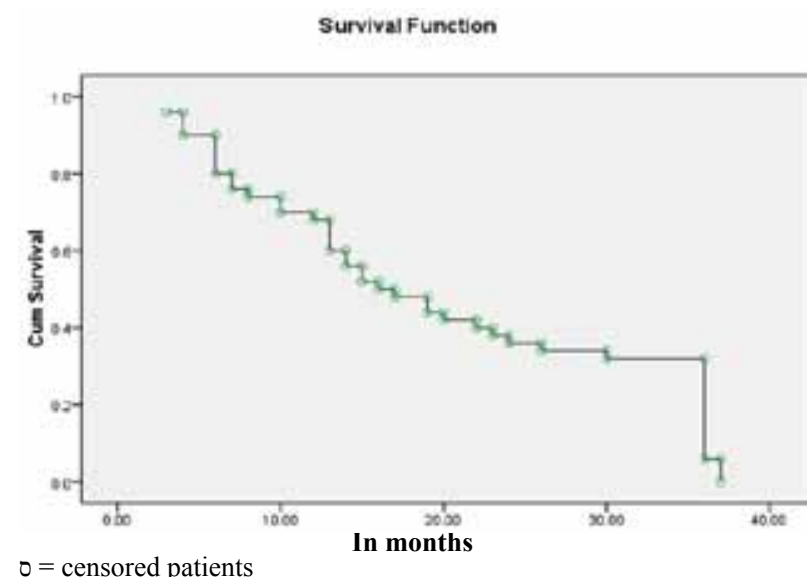

Figure 2: Disease free survival (dfs) of 50 patients with advanced head and neck cancer treated by alternating chemoradiotherapy.

$-95 \%$ confidence interval 10.225-21.775.

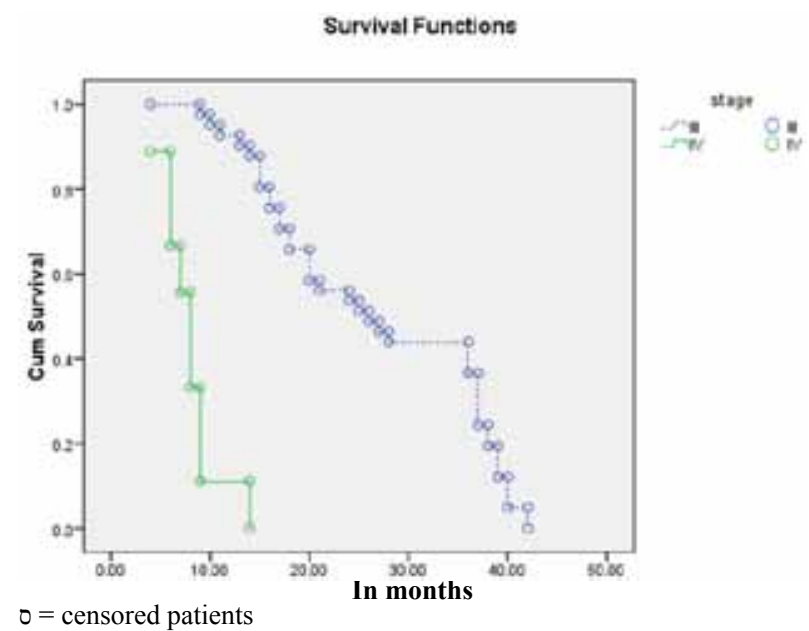

Figure 3: Stage of the disease as a prognostic factor for survival of 50 patients with locally advanced head and neck cancer treated by alternating chemoradiotherapy (stage III vs IV, $P<.001$ ).

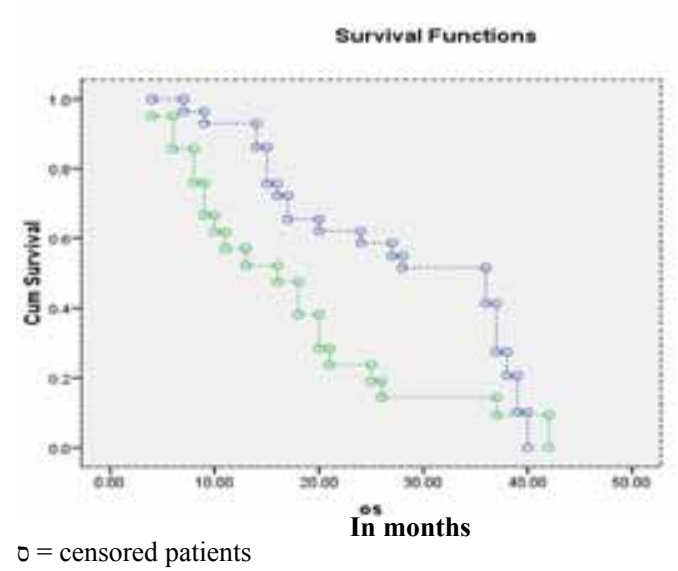

Figure 4: Pathological grade as a prognostic factor for survival of 50 patients with locally advanced head and neck cancer treated by alternating chemoradiotherapy (grade I\& II vs III, $P<.003)$

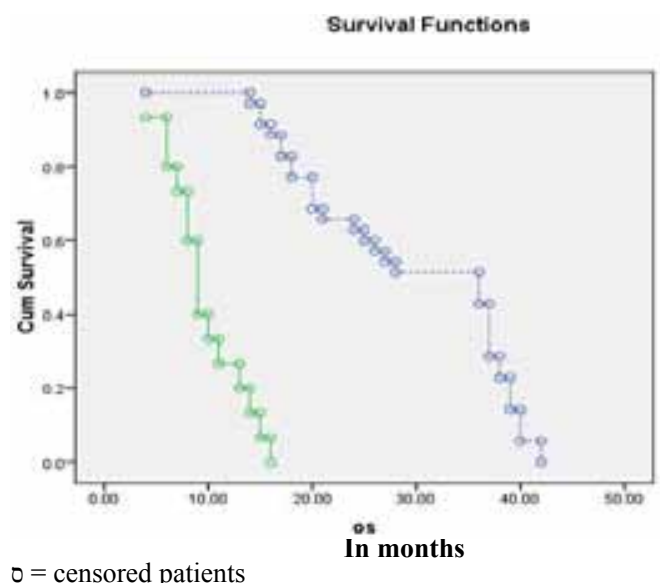

Figure 5: Performance status (ECOG) as a prognostic factor for survival of 50 patients with locally advanced head and neck cancer treated by alternating chemoradiotherapy $(0$ vs $1, P<.001)$.

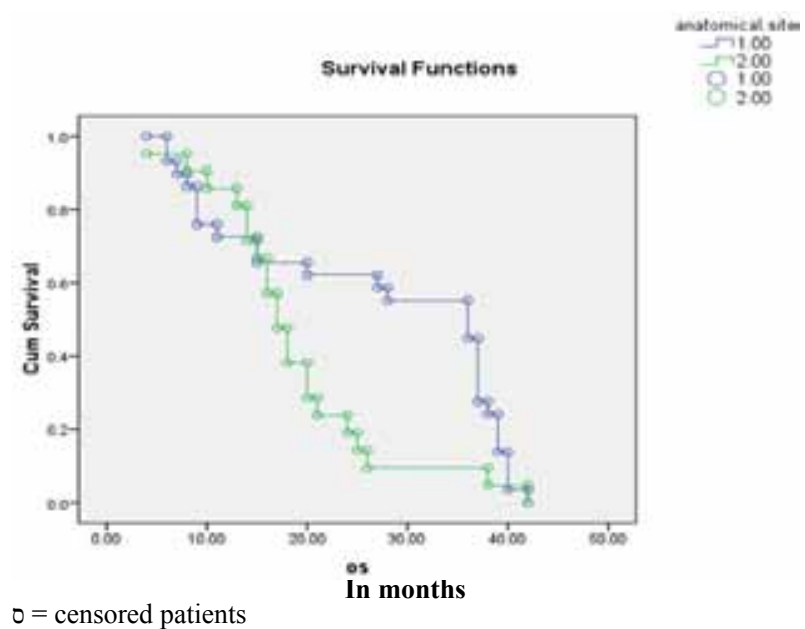

Figure 6: Anatomical site as a prognostic factor for survival of 50 patients with locally advanced head and neck cancer treated by alternating chemoradiotherapy (larynx vs hypopharynx, $P<.023$ ). 


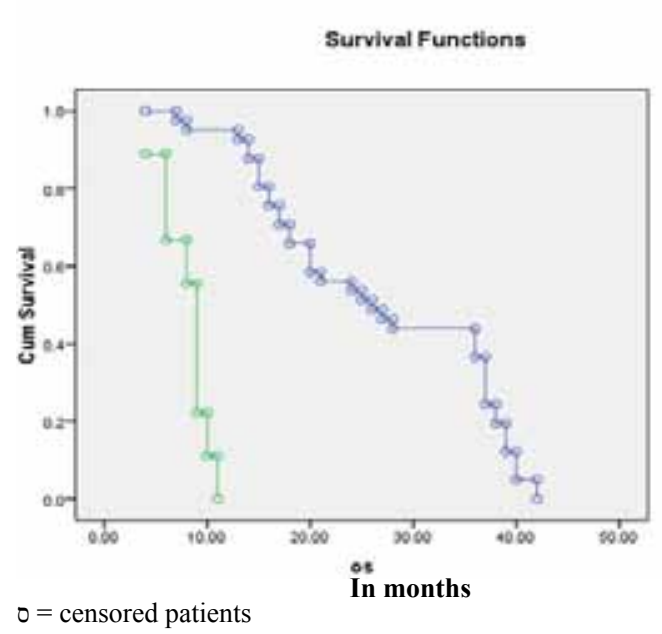

Figure 7: Nodal state as a prognostic factor for survival of 50 patients with locally advanced head and neck cancer treated by alternating chemoradiotherapy (node $-\mathrm{ve}$ vs. node $+\mathrm{ve}, P<.001$ ).
Table 1: Patients Characteristics.

\begin{tabular}{lc}
\hline Patient character & Patient number (\%) \\
\hline Age & $11(22 \%)$ \\
$\leq 40$ & $9(18 \%)$ \\
$41-50$ & $10(20 \%)$ \\
$51-60$ & $20(40 \%)$ \\
$>60$ & 54.7 (standard deviation 13.94$)$ \\
Mean age (range 40-60) & \\
Sex & $33(66 \%)$ \\
Male & $17(34 \%)$ \\
Female & \\
\hline Performance Status (ECOG) & $35(70 \%)$ \\
Grade (0) & $15(30 \%)$ \\
Grade (1) & \\
\hline Clinical Staging & $42(84 \%)$ \\
Stage III & $8(16 \%)$ \\
Stage IVA &
\end{tabular}

Table 2: Tumor (T) and node (N) Staging.

\begin{tabular}{lllllc}
\hline & $\mathbf{T}_{\mathbf{1}}$ & $\mathbf{T}_{\mathbf{2}}$ & $\mathbf{T}_{\mathbf{3}}$ & $\mathbf{T}_{\mathbf{4}}$ & Total \\
\hline $\mathrm{N}_{0}$ & - & - & 36 & 5 & 41 \\
\hline $\mathrm{N}_{1}$ & - & - & 6 & 1 & 7 \\
\hline $\mathrm{N}_{2}$ & - & - & - & 2 & 2 \\
\hline Total & - & - & 42 & 8 & 50 \\
\hline
\end{tabular}

Table 3: Tumor Site and Histopathological Grading.

\begin{tabular}{lc}
\hline Endoscopic Site & Number (\%) \\
\hline Larynx & $10(20 \%)$ \\
Supraglottic & $18(36 \%)$ \\
Transglottic & $11(22 \%)$ \\
\hline Hypopharynx & $2(4 \%)$ \\
Postcricoid & $9(18 \%)$ \\
Pharyngeal wall & \\
Pyriform sinus & $41(82 \%)$ \\
\hline Nodal metastases & $9(18 \%)$ \\
(-ve) lymph nodes enlargement & \\
(+ve) lymph nodes enlargement & $12(24 \%)$ \\
\hline Pathological grading & $17(34 \%)$ \\
Grade1 & $21(42 \%)$ \\
Grade2 &
\end{tabular}

(-ve): no lymph node enlargment

(+ve): lymph node enlarged 
Kasr-El-Aini Journal Of Clinical Oncology And Nuclear Medicine

Vol. 8 | No. 1-2 2012

Alternating Combination Chemotherapy and Radiotherapy

Table 4: Prognostic Factors for Response to Alternating Chemoradiotherapy.

\begin{tabular}{|c|c|c|c|c|c|}
\hline Prognostic factors & CR(\%) & $\operatorname{PR}(\%)$ & $\operatorname{SD}(\%)$ & PD(\%) & $\mathbf{P}-\mathbf{V}$ \\
\hline \multicolumn{6}{|l|}{ Age } \\
\hline$<55 y$ & $19(76)$ & $4(16)$ & - & $2(8)$ & \multirow[t]{2}{*}{0.74} \\
\hline$\geq 55 y$ & $17(68)$ & $5(20)$ & 1(4) & $2(8)$ & \\
\hline $\begin{array}{l}\text { Performance state } \\
\text { Grade } 0 \\
\text { Grade } 1\end{array}$ & $\begin{array}{c}27(79) \\
9(56)\end{array}$ & $\begin{array}{l}5(15) \\
4(25)\end{array}$ & $\begin{array}{c}1(3) \\
-\end{array}$ & $3(19)$ & 0.15 \\
\hline \multicolumn{6}{|l|}{ Anatomical site } \\
\hline Laryngeal & $23(82)$ & $4(14)$ & 1(4) & - & \multirow[t]{2}{*}{0.04} \\
\hline Hypopharyngeal & $13(59)$ & $5(23)$ & - & $4(18)$ & \\
\hline \multicolumn{6}{|l|}{ Cervical lymph node } \\
\hline$-\mathrm{Ve}$ & $34(83)$ & $5(12)$ & - & $2(5)$ & \multirow[t]{2}{*}{0.002} \\
\hline$+\mathrm{Ve}$ & $2(22)$ & $4(45)$ & $1(11)$ & $2(22)$ & \\
\hline \multicolumn{6}{|l|}{ Staging } \\
\hline Stage III & $34(81)$ & $6(14)$ & - & $2(5)$ & \multirow{2}{*}{0.003} \\
\hline Stage IV A & $2(25)$ & $3(38)$ & $1(12)$ & $2(25)$ & \\
\hline \multicolumn{6}{|l|}{ Grading } \\
\hline Grade 1 & $10(84)$ & 0 & $1(8)$ & $1(8)$ & \multirow{3}{*}{0.175} \\
\hline Grade 2 & $13(76)$ & $4(24)$ & 0 & 0 & \\
\hline Grade 3 & $13(62)$ & $5(24)$ & 0 & $3(14)$ & \\
\hline
\end{tabular}

CR: complete response

PR: partial response

SD: stable disease

PD: progressive disease

Table 5: RTOG EORTC Radiation Toxicity Among 50 Patients with Locally Advanced Head and Neck Cancer Treated by Alternating Chemo-radiotherapy.

\begin{tabular}{lcc}
\hline Toxicity & Grade & No. (\%) \\
\hline Mucositis & G1 & 28(56) \\
& G2 & $5(10)$ \\
\hline Xerostomia & G3 & $21(42)$ \\
& G1 & 26(52) \\
\hline Dysphagia & G2 & $3(6)$ \\
& G3 & $2(4)$ \\
& G0 & $16(32)$ \\
& G1 & $18(36)$ \\
\hline Stomatitis & G2 & $14(28)$ \\
\hline Dermatitis & G3 & $6(12)$ \\
& G1 & $28(56)$ \\
& G2 & $9(18)$ \\
\hline & G3 & $7(14)$ \\
\hline
\end{tabular}




Vol. 8 | No. 1-2 $2012 \quad$ Hanan Gamal-Eldin et al.

\section{DISCUSSION}

Alternating chemotherapy and radiotherapy has been tested in advanced head and neck cancer and has shown superiority over standard radiation in some randomized trials with only marginally greater toxicity ${ }^{10}$. The biological mechanisms of interaction between chemotherapy and radiotherapy include interactions at the molecular, cellular and tissue levels. At the molecular level, radiation and drugs cooperate to target DNA, by increasing DNA damage and interfering with DNA repair. At the cellular level, chemoradiation may induce cytokinetic cooperation. Radiosenstivity changes during the phases of the cell cycle. The S-phase is the most radioresistant, whereas S-phase cells are highly sensitive to several anticancer drugs. This is the reason why a greater cell kill is observed when proliferating cells are exposed to drugs and radiation in close temporal proximity ${ }^{11}$.

There is one additional mechanism of action that may be ascribed to ACR. The breaks between radiotherapy treatments (that result in tumor repopulation) are filled up with chemotherapy. Therefore, a cytokinetic mechanism of cooperation, exploiting tumor repopulation, may be at work in $\mathrm{ACR}^{12}$.

At the tissue level, cooperation between radiation and the chemotherapy drugs is the result of rapid tumor shrinkage and reoxygenation resulting from an improved blood supply. This effect could be related to a reduction in interstitial pressure ${ }^{13}$.

The present study design is similar to the original trials used vinblastine, bleomycin and methotrexate (VBM) and radiotherapy was delivered as a standard single daily fraction in an alternating schedule ${ }^{14}$. The present study shows a complete response (CR) $72 \%$, disease-free survival (DFS) and overall survival (OS) at 3years, 32\% and $30 \%$, respectively. This is not in agrement with the results of Merlano et al. ${ }^{14}$ who used the same schedule and reported CR 33\%, DFS and OS at 4 years $12 \%$ and $22 \%$, respectively. The difference may be due to the high percentage of patients with stage IV in his study.

The schema of VBM was replaced with the combination of cisplatin and fluorouracil in light of the accepted superiority of this regimen. Fluorouracil was added to cisplatin because of the supposed synergism between the two drugs. More over, it was delivered as an IV bolus to minimize mucosal toxicity, which is mainly induced by the continuous infusion of the drug. In this way, the overlapping mucosal toxicity between chemotherapy and radiotherapy is intheory reduced ${ }^{10}$.

Two studies used ACR schedule with the combination of cisplatin and fluorouracil. The first one done by
Merlano et al..$^{5}$ who compare ACR and radiotherapy alone, CR was achieved in $42 \%$, 3years OS was $41 \%$ which were significantly higher than radiotherapy alone. The second study was done by Corvo et al. ${ }^{15}$ who reported 3 years OS 37\% and DFS 35\%. The lower OS and DFS in the present study compared with their results may be due to the high percentage of hypopharyngeal carcinoma $44 \%$, high percentage of grade III carcinoma $42 \%$ and non-surgical management of locoregional recurrence in the present study.

Alternating chemoradiotherapy in locally advanced $\mathrm{HNC}$, regardless of the chemotherapy regimens is more likely to be associated with complete respons $\mathrm{e}^{16}$. To increase the response of ACR induction chemotherapy was given before it as in the study done by Benasso et al. ${ }^{17}$ who reported CR $86.7 \%$, PR $13.3 \%$, 3years DFS and OS, $64 \%$ and $83 \%$, respectively.

An investigational program to explore a modified alternating regimen (cisplatin + fluorouracil) was done by Benasso et al. ${ }^{18}$ including gemcitabine given both with radiosenstizing and cytotoxic intent. Complete response was achieved in $72 \%$, 3years OS and DFS was $43 \%$ and $39 \%$, respectively. Data of locoregional control favorably compared with those from database of patients treated with alternating cisplatin-fluorouracil and radiation within controlled clinical trials (64\% versus $40 \%$ ).

Another trial done by Benasso et al. ${ }^{19}$ who added gemcitabine to the alternating cisplatin-fluorouracil and reported that the addition of gemcitabine at low dose $\left(50 \mathrm{mg} / \mathrm{m}^{2}\right.$ on each Monday of radiotherapy) is feasible and very active. It may improve long-term outcomes despite an acceptable increase of acute mucosal toxicity.

The combination of chemotherapy and radiotherapy inevitably induces more toxic effects than each modality alone. Stomatitis is the major toxic effect of ACR and appears to be strictly related to the chosen drugs and scheduling. Merlano et al. ${ }^{14}$ who used VBM schedule reported a grade III-IV stomatitis $31 \%$. Corvo et al. ${ }^{15}$ and Fuwa et al..$^{20}$ reported $33 \%$ and $31 \%$ grade III-IV stomatitis with cisplatin-fluorouracil regimen in ACR schedule, all these results are inagrement with the results of the present study.

The addition of gemcitabine to ACR schedule resulted in $81 \%$ of 47 treated patients to develop grade III-IV stomatitis which is much higher than the previous results. This can be explained by the use of gemcitabine as a radiosentizer and cytotoxic drug. Another published phase II trial based on ACR done by Merlano et al. ${ }^{21}$ who added paclitaxel to cisplatin-fluorouracil and grade III-IV stomatitis occurred in $81 \%$ of the 31 treated patients. 


Vol. 8 | No. 1-2 2012

A direct comparison between ACR and concurrent chemoradiation (CCR) does not exist, but some studies reported a similar response in both schedules. A study done by Cohen et al. ${ }^{22}$ who used fluorouracil+hydroxyurea with hyperfractionated radiotherapy, the other study done by Adelstein et al. ${ }^{23}$ who used concurrent cisplatinfluorouracil and conventional radiotherapy. Both studies show the same response to therapy as ACR.

As regard one-year DFS and OS in the present study which was $70 \%$ and $78 \%$, respectively, it is comparable with the one-year DFS and OS of the study done by Montejo et al. ${ }^{24}$ which was $73 \%$ and $73 \%$, respectively on CCR, but the 2-years DFS and OS in his study was $73 \%$ and $65 \%$ which is higher than the present study this is may be due to the use of IMRT in his trial.

In a study done by Specenier et al. ${ }^{25}$ who used CCR and reported a high percentage of non-hematological toxicity, and also Watkins et al. ${ }^{26}$ reported a grade III mucositis, nausea and neutropenia, $61 \%, 27 \%$ and $81 \%$, respectively which is higher than the present study. This suggests a more favorable toxicity profile of ACR.

As regard the prognostic factors for response to treatment with ACR in the present study, the anatomical site $(P=0.04)$, nodal stage $(P=0.002)$ and stage of the disease $(P=0.003)$ were significant prognostic factors. This is in agrement with the results reported by Benasso et $a l .{ }^{16}$ who revealed that the size of the primary tumor $(P=0.004)$, nodal involvement $(P=0.02)$ and performance status $(P=0.009)$ are prognostic variables affecting the probability of achieving a complete response.

Prognostic factors significant for survival in the present study were performance status, pathological grade, anatomical site, stage of the disease and nodal stage. This is inagrement with the results reported by Khademi et al..$^{27}$ according to their multivariate analysis of OS, patients under 40 years, node stage and stage of the disease were significant prognostic factors. Another study done by Vermorken et al. ${ }^{28}$ revealed that tumor differentiation, ECOG performance status, weigh loss and location of the primary were significant prognostic factors.

\section{CONCLUSION}

Alernating chemotherapy and radiotherapy shows a promising activity and low toxicity in locally advanced head and neck cancer treatment. However, a randomized trials comparing alternating chemoradiation with concurrent chemoradiation are mandatory in order to definitely establish the role of these two different schedules of chemoradiation.
Alternating Combination Chemotherapy and Radiotherapy

\section{REFERENCES}

1. Gil Z, Fliss DM. Contemporary management of head and neck cancers. Israel Med.Assoc.J. 2009;11(5):296-300.

2. Nagler RM, Reznick AZ. Cigarette smoke effects on salivary antioxidants and oral cancer - Novel concepts. Israel Med.Assoc.J. 2004;6(11):691-4.

3. Shah JP, Gil Z. Current concepts in management of oral cancer - Surgery. Oral Oncol. 2009;45(4-5):394-401.

4. Haffty BG. Concurrent chemoradiation in the treatment of head and neck cancer. Hematol.Oncol.Clin.North Am. 1999;13(4):719-42.

5. Merlano M, Vitale V, Rosso R, Benasso M, Corvo R, Cavallari $\mathrm{M}$, et al. Treatment of advanced squamous-cell carcinoma of the head and neck with alternating chemotherapy and radiotherapy. N.Engl.J.Med. 1992;327(16):1115-21.

6. Pignon JP, Bourhis J, Domenge C, Designé L. Chemotherapy added to locoregional treatment for head and neck squamous-cell carcinoma: Three meta-analyses of updated individual data. Lancet 2000; 355(9208):949-55.

7. Merlano M, Marchetti G. Radiochemotherapy in head and neck cancer. Cancer Treat.Rev. 2003;29(4):291-6.

8. Miller AB, Hoogstraten B, Staquet M, Winkler A. Reporting results of cancer treatment. Cancer 1981;47(1):207-14.

9. Kaplan EL, Meier P. Non-parametric estimation for incomplete observation. J.Am.Stat.Assoc. 1958;53:457-81.

10. Merlano M. Alternating chemotherapy and radiotherapy in locally advanced head and neck cancer: An alternative? Oncologist 2006;11(2):146-51.

11. Hennequin C, Favaudon V. Biological basis for chemoradiotherapy interactions. Eur.J.Cancer 2002;38(2):223-30.

12. Glynne Jones R, Sebag Montefiore D. Chemoradiation schedules - What radiotherapy? Eur.J.Cancer 2002;38(2):258-69.

13. Koukourakis MI. Tumour angiogenesis and response to radiotherapy. Anticancer Res. 2001;21(6 B):4285-300.

14. Merlano M, Corvo R, Margarino G, Benasso M, Rosso R, Sertoli MR, et al. Combined chemotherapy and radiation therapy in advanced inoperable squamous cell carcinoma of the head and neck. The final report of a randomized trial. Cancer 1991;67(4):915-21.

15. Chua DTT, Sham JST, Wei WI, Ho WK, Au GKH. Alternating chemoradiotherapy versus partly accelerated radiotherapy in locally advanced squamous cell carcinoma of the head and neck: Results from a phase III randomized trial. Cancer 2001; 92(11):2856-67.

16. Benasso M, Bonelli L, Numico G, Corvò R, Sanguineti G, Rosso R, et al. Treatment with cisplatin and fluorouracil alternating with radiation favourably affects prognosis of inoperable squamous cell carcinoma of the head and neck: Results of a multivariate analysis on 273 patients. Ann. Oncol. 1997;8(8):773-9.

17. Benasso $M$, Sanguineti $G$, D'Amico $M$, Corvò $R$, Ricci I, Numico G, et al. Induction chemotherapy followed by alternating chemo-radiotherapy in stage IV undifferentiated nasopharyngeal carcinoma. Br.J.Cancer 2000;83(11):1437-42. 


Vol. 8 | No. 1-2 $2012 \quad$ Hanan Gamal-Eldin et al.

18. Benasso M, Corvò R, Ponzanelli A, Sanguineti G, Ricci I, Pallestrini E, et al. Alternating gemcitabine and cisplatin with gemcitabine and radiation in stage IV squamous cell carcinoma of the head and neck. Ann.Oncol. 2004;15(4):646-52.

19. Benasso M, Vigo V, Bacigalupo A, Ponzanelli A, Marcenaro M, Corvò $\mathrm{R}$, et al. A phase II trial of lowdose gemcitabine and radiation alternated to cisplatin and 5-fluorouracil: An active and manageable regimen for stage IV squamous cell carcinoma of the head and neck. Radiother.Oncol. 2008;89(1):44-50.

20. Fuwa N, Kano M, Toita T, Shikama N, Kodaira T, Matsumoto A, et al. Alternating chemoradiotherapy for nasopharyngeal cancer using cisplatin and 5-fluorouracil: A preliminary report of phase II study. Radiother.Oncol. 2001;61(3):257-60.

21. Merlano M, Russi EG, Numico G, Colantonio I, Garrone O, Pelissero A, et al. Paclitaxel, cisplatin, 5-fluorouracil and radiotherapy in the management of advanced squamous cell carcinoma of the head and neck. A phase II trial. Radiother.Oncol. 2005;75(2):193-6.

22. Cohen EEW, Haraf DJ, List MA, Kocherginsky M, Mittal BB, Rosen $\mathrm{F}$, et al. High survival and organ function rates after primary chemoradiotherapy for intermediate-stage squamous cell carcinoma of the head and neck treated in a multicenter phase II trial. J.Clin.Oncol. 2006;24(21):3438-44.
23. Adelstein DJ, Saxton JP, Rybicki LA, Esclamado RM, Wood BG, Strome M, et al. Multiagent concurrent chemoradiotherapy for locoregionally advanced squamous cell head and neck cancer: Mature results from a single institution. J.Clin.Oncol. 2006;24(7):1064-71.

24. Montejo ME, Shrieve DC, Bentz BG, Hunt JP, Buchman LO, Agarwal N, et al. IMRT with simultaneous integrated boost and concurrent chemotherapy for locoregionally advanced squamous cell carcinoma of the head and neck. Int.J.Radiat.Oncol.Biol.Phys. 2011;81(5):e845-52.

25. Specenier PM, Van den Weyngaert D, Van Laer C, Weyler J, Van den Brande J, Huizing MT, et al. Phase II feasibility study of concurrent radiotherapy and gemcitabine in chemonaive patients with squamous cell carcinoma of the head and neck: Long-term follow up data. Ann.Oncol. 2007;18(11):1856-60.

26. Watkins JM, Zauls AJ, Wahlquist AH, Shirai K, Garrett Mayer E, Gillespie MB, et al. Low-dose weekly platinumbased chemoradiation for advanced head and neck cancer. Laryngoscope 2010;120(2):236-42.

27. KhademiB,MahmoodiJ, OmidvariS, Mohammadianpanah M. Treatment results of nasopharyngeal carcinoma: A 15year single institutional experience. J.Egypt.Natl.Cancer Inst. 2006;18(2):147-55.

28. Vermorken JB, Specenier P. Optimal treatment for recurrent/metastatic head and neck cancer. Ann.Oncol. 2010;21(Suppl. 7):vii252-61. 